\title{
Optimal integration of DGs into radial distribution network in the presence of plug-in electric vehicles to minimize daily active power losses and to improve the voltage profile of the system using bio- inspired optimization algorithms
}

Satish Kumar Injeti ${ }^{*}$ and Vinod Kumar Thunuguntla

\begin{abstract}
Purpose: The increase in plug-in electric vehicles (PEVs) is likely to see a noteworthy impact on the distribution system due to high electric power consumption during charging and uncertainty in charging behavior. To address this problem, the present work mainly focuses on optimal integration of distributed generators (DG) into radial distribution systems in the presence of PEV loads with their charging behavior under daily load pattern including load models by considering the daily ( $24 \mathrm{~h}$ ) power loss and voltage improvement of the system as objectives for better system performance.

Design/methodology/approach: To achieve the desired outcomes, an efficient weighted factor multi-objective function is modeled. Particle Swarm Optimization (PSO) and Butterfly Optimization (BO) algorithms are selected and implemented to minimize the objectives of the system. A repetitive backward-forward sweep-based load flow has been introduced to calculate the daily power loss and bus voltages of the radial distribution system. The simulations are carried out using MATLAB software.

Findings: The simulation outcomes reveal that the proposed approach definitely improved the system performance in all aspects. Among PSO and BO, BO is comparatively successful in achieving the desired objectives.

Originality/value: The main contribution of this paper is the formulation of the multi-objective function that can address daily active power loss and voltage deviation under 24-h load pattern including grouping of residential, industrial and commercial loads. Introduction of repetitive backward-forward sweep-based load flow and the modeling of PEV load with two different charging scenarios.
\end{abstract}

Keywords: Plug-in electric vehicles (PEVs), Distributed generators (DGs), Repetitive distribution power flow, Particle swarm optimization algorithm (PSO), Butterfly optimization (BO), Daily active power loss

\footnotetext{
* Correspondence: drinjetisatishkumar@nitw.ac.in

Department of Electrical Engineering, National Institute of Technology

Warangal, Telengana State 506004, India
} 


\section{Introduction}

DG (Distributed Generator) is characterized as a local power source with a constrained size associated with the distribution network. DGs Technology has turned into the focal point of consideration for various researchers because it is considered a proper answer for the shortage of electric power supply. Moreover, proper installation of DGs in the distribution system increases the efficiency of the system, improves voltage profile and voltage stability of the system and release of line loading. However, improvement in the above mentioned technical parameters mostly depends on finding the right locations and proper sizing of DGs which is termed as the optimal allocation of DGs. Therefore, an optimal allocation of DGs in a distribution system aims to determine the optimal locations and optimal sizes of DGs to meet active power loss reduction, voltage profile improvement, etc., subject to various constraints such as power demand, voltage limit, DGs size, Maximum power injection by DGs, etc.

Some authors have presented a review of the optimal allocation of DGs in the distribution system [1,2]. Various researchers have developed a variety of methods for the optimal allocation of DGs in radial distribution networks [3-14]. Satish Kumar et al. proposed a simulated annealing algorithm for the sizing of multiple DGs to reduce system active power loss. Loss sensitivity indexes have been used for finding locations for DGs [3]. AbuMount et al. proposed an artificial honey bee colony technique for the optimal allocation of DGs for the minimization of active power losses in the network [11]. Martín García et al. proposed the optimal allocation of DGs in the distribution network utilizing a modified teaching learning-based optimization algorithm with a goal of minimization of active power losses [8]. It has been observed that finding locations and sizes of DGs simultaneously yields good results rather than finds locations by sensitivity indices and then the size of DGs by an optimization algorithm. Therefore, in this paper, the simultaneous optimal allocation of DGs has been implemented using two bio-inspired optimization algorithms.

Many researchers have developed a weighted factor multi-objective function to gain multiple benefits due to the optimal placement of DGs in the distribution system. El-Zonkoly presented Particle Swarm Optimization for the optimal sitting of various DGs in a distribution network including voltage-dependent load models by aggregated weighted multi-objective optimization approach [13]. Sultana et al. formulated a weighted factor multi-objective function which addresses three benefits of optimal placement of DGs: power loss reduction, voltage profile improvement, and voltage stability improvement [12]. The quasi oppositional teaching learning-based optimization algorithm has used for the minimization of multi-objective function. Mohamed et al. presented a bacterial foraging optimization algorithm for minimization of multi-objective function which comprises power loss, voltage deviation and operating cost of the system [7]. Attia El-Fergany presented a backtracking search algorithm based on the optimal allocation of DGs in the distribution network. Aggregated weight adaptive objective function is utilized to reduce the system's active power losses and upgrade the voltage profile [9].S K Injeti, presented a Pareto optimizationbased improved differential search algorithm for optimal allocation of DGs in radial distribution networks to minimize total operating cost, bus voltage deviation, and active power losses simultaneously [6]. In these papers, the authors considered the optimal allocation of DGs under peak load condition only. It has been observed that the minimization of a multi-objective function gives a trade-off solution between active power loss reduction, voltage deviation minimization, and voltage stability improvement. So, in this paper, we have formulated a weighted factor multi-objective function which will addresses minimization of power loss and voltage deviation for simultaneous optimal allocation of DGs under time varying load pattern (with different load models) of the distribution system.

Some authors have addressed the optimal placement of DGs by considering few load levels of the distribution system. R. S Rao et al. presented a method for optimal placement of DGs in different load levels under an optimally reconfigured network for power loss minimization [4]. B Poornazaryan et al. proposed a new index for optimal allocation of DG units to minimize active power losses and to enhance voltage stability margin by considering load variations. Linear load variations from $50 \%$ to $150 \%$ of base load with a step size of $1 \%$ and in each step size optimal DGs sizes are obtained [10]. Neeraj K et al. proposed an improved cat swarm optimization algorithm for optimal placement of DG and distributed static compensator under a multilevel load profile for power loss minimization [15]. Neeraj Kanwar et al. proposed a new methodology to provide an integrated solution for the optimal allocation of distributed generators and network reconfiguration considering load patterns of customers for the maximization of annual energy loss reduction [5]. In these papers, researchers have concentrated on the optimal placement of DGs under few load levels or linear load variations from $50 \%$ to $150 \%$ of base load. But a practical distribution system consists of a combination of residential buses, commercial buses, and industrial buses. Linear load variation is not possible for such a distribution system. Because a particular hour in a day if the residential bus load level is $0.8 \mathrm{p} . \mathrm{u}$ with respect to peak level 1p.u, the commercial bus load level may be other than 0.8 p.u. Due to uneven load level among the 
different types of buses, the optimal locations of DGs may vary hour by hour or may not be the same, which increases the complexity of the problem. Therefore, in this paper, we have formulated a weighted multiobjective function addresses daily active power loss minimization; daily voltage profile improvement of a distribution system consists of residential, commercial and industrial loads with 24-h load pattern.

The developing worries over $\mathrm{CO}_{2}$ emissions and the greenhouse effect have motivated the shift towards the zero-emission plug-in battery fueled electric vehicles (PEVs) which are expected to play a noteworthy part in making the road transport system. Authors $[16,17]$ addressed dynamic economic dispatch problem by integrating PEVs charging profiles into a 24-h load demand in an economic and environmental dispatch problem. A detailed review of electric vehicle technologies and the impact of PEVs electric demand on load profiles were given in [18]. Kejun Qian et al. proposed a methodology for modeling of PEVs battery charging load and study the impacts of PEVs on distribution system performance under four charging scenarios [19]. Four charging scenarios are modeled and simulated based on the charging behavior of the vehicles. LI Hui-ling et al. presented the impacts of PEVs charging behavior on distribution grid [20]. However few papers have addressed the mitigation of impacts of PEVs load under different charging behavior via optimal placement of DGs in the distribution system.

In this paper, two PEVs charging scenarios, off-peak charging scenario and peak charging scenarios that are modeled using charging time probability distribution are considered. These two charging time probability functions are measured with a certain number of PEVs and then integrated into the daily load pattern of the distribution system which consists of residential, commercial and industrial buses. Then a detailed analysis of the impacts of the PEVs behavior under two charging scenarios is addressed. As PEVs deteriorate distribution system performance, in this paper DGs are considered to improve the performance of the distribution system with PEVs which requires optimal allocation of DGs. Like the aforementioned, a weighted multi-objective function is formulated for optimal allocation of multiple DGs (power factor-based) in a distribution system with PEVs. Two optimization algorithms PSO and BO are very popular and efficient chosen for optimization of the proposed objective function.

The remaining of the paper is organized as follows; section 2 formulates a mathematical model for optimal allocation of DGs in distribution system with PEVs charging followed by section 3 the implementation of PSO and $\mathrm{BO}$ algorithms to the proposed optimization problem has been presented. Section 4 gives the comparative analysis between the distribution system without PEVs and with PEVs charging scenarios and also presented the comparison between without DGs and with DGs on distribution system with PEVs.

\section{Problem formulation}

\subsection{Modeling of DGs}

For load flow studies, DGs can be model as either PV mode or PQ mode [21]. In this paper, DG is modeled as PQ mode. In this type of modeling, DG is modeled as a generating source (negative load model) with constant active power output $\left(P_{D G}\right)$ and reactive power output $\left(Q_{D G}\right)$. In this type of modelling, active power and power factor (PF) of the DG is mentioned. Reactive power of the DG is calculated by using Eq. 1 .

$$
Q_{D G}=P_{D G} *\left(\tan \left(\cos ^{-1} P F\right)\right)
$$

The effective load at any bus with the integration of DG unit can be expressed as

$$
\begin{aligned}
& P_{\text {eff,load }}=P_{\text {load }}-P_{D G} \\
& Q_{\text {eff,load }}=Q_{\text {load }}-Q_{D G}
\end{aligned}
$$

Where $P_{\text {load }}, Q_{\text {load }}$ active and reactive power demands at the bus are, $P_{\text {eff, load }}, Q_{\text {eff, load }}$ are the effective active and reactive power demands at the bus after the placement of DG.

\subsection{Objective function}

In this paper, a weighted multi-objective function (OF) is formulated which addresses daily active power loss reduction and voltage deviation index reduction.

$$
\min \{O F\}=(w 1 * P L R I)+(w 2 * V D I R I)
$$

Where, $w 1$ and $w 2$ are weighting factors, PLRI- Power loss reduction index and VDIRI- voltage deviation index reduction index. The range of weighting factors is 0 to 1 , which are user-defined. The sum of the weighting factors should always be equal to one.

\subsubsection{Power loss reduction index (PLRI)}

The daily power loss of the system can be reduced by minimizing PLRI which is taken as the ratio of system daily active power loss after placement of DGs $\left(P_{\text {loss,daily }}^{D G}\right)$ to the system daily active power loss before placement of DGs $\left(P_{\text {loss, daily }}\right)$.

$$
P L R I=\frac{P_{\text {loss,daily }}^{D G}}{P_{\text {loss,daily }}}=\frac{\sum_{j=1}^{24} P_{j \text { loss }}^{D G}}{\sum_{j=1}^{24} P_{\text {jloss }}}
$$

Where $P_{j l o s s}$ is the $j^{\text {th }}$ hour system active power loss before placement of DGs [22], $P_{j l o s s}^{D G}$ is the $j^{\text {th }}$ hour system active power loss after placementhe $t$ of DGs. 


\subsubsection{Voltage deviation index reduction index (VDIRI)}

Voltage profile through the day can be improved by minimizing VDIRI which is the ratio of voltage deviation index with DGs to the voltage deviation index without DGs.

$$
V D I R I=\frac{V D I^{D G}}{V D I^{W O D G}}=\frac{\sum_{j=1}^{24} \max \left(1-\left|U_{j, i}^{D G}\right|\right)}{\sum_{j=1}^{24} \max \left(1-\left|U_{j, i}\right|\right)} i=1,2 \ldots \ldots n b
$$

Where, $\left|U_{j, i}\right|$ the voltage magnitude of $i^{\text {th }}$ bus is during $j^{\text {th }}$ hour in p.u before placement of DGs $\left|U_{j, i}^{D G}\right|$ is the voltage magnitude of $i^{t h}$ bus during $j^{\text {th }}$ hour in p.u after placement of DGs.

\subsubsection{Constraints}

1. Active power and reactive power balance constraints.

$$
\begin{aligned}
& P_{j, s u b}+P_{T, D G}=P_{j, D}+P_{j l o s s} \\
& Q_{j, s u b}+Q_{T, D G}=Q_{j, D}+Q_{j l o s s}^{D G}
\end{aligned}
$$

Where

$$
\begin{aligned}
& P_{j, \text { sub }}=\left|U_{j, \text { sub }}\right| *\left|I_{j .1}\right| * \cos \left(\angle U_{j, s u b}-\angle I_{j .1}\right) \\
& Q_{j, \text { sub }}=\left|U_{j, \text { sub }}\right| *\left|I_{j .1}\right| * \cos \left(\angle U_{j, s u b}-\angle I_{j .1}\right) \\
& P_{j, D}=\sum_{i=1}^{n b}\left(P_{\text {bus } j, i}+P_{P E V ~ j, i}\right) \\
& Q_{j, D}=\sum_{i=1}^{n b}\left(Q_{b u s j, i}\right)
\end{aligned}
$$

Where $P_{j \text {, sub }}$ is the $j^{\text {th }}$ hour active power demand supplied by sub-station in $\mathrm{kW}, P_{j, D}$ is $j^{\text {th }}$ hour total active power demand of the system with $P E V \mathrm{~s}$ in $\mathrm{kW}, Q_{j, \text { sub }}$ is the $j^{\text {th }}$ hour reactive power supplied by sub-station in kVAr, $Q_{j, D}$ is the $j^{\text {th }}$ hour total reactive power demand of the system with PEVs in kVAr, $\left|U_{j, s u b}\right|$ is the substation bus voltage during $j^{\text {th }}$ hour in $\mathrm{kV},\left|I_{1}\right|$ is the 1 st branch current in amps during $j^{\text {th }}$ hour, $P_{\text {bus } j, i}$ is the $i^{\text {th }}$

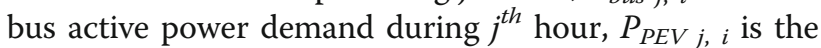
$i^{\text {th }}$ bus active power demand due to PEV in $j^{\text {th }}$ hour.

2. The voltage magnitude of each bus should be within the minimum and maximum voltage limits.

$$
\left|U_{\min }\right|<\left|U_{i}\right|<\left|U_{\max }\right| i=1,2 \ldots \ldots \ldots n b
$$

3. The sizes of DGs to be placed should be within minimum and maximum $\mathrm{kW}$ limit.

$$
P_{D G m i n}<P_{k, D G}<P_{D G \max } k=1,2 \ldots \ldots . . n d g
$$

4. Total active power compensation by DGs should be less than or equal to the maximum total capacity of DGs $\left(P_{T, D G}^{\max }\right)$ which is the user-defined variable and minimum total active power demand throughout the day.

$$
P_{T, D G} \leq P_{T, D G}^{\max }<\min \left(P_{j, D}\right)
$$

\subsection{PEVs charging scenario}

Based on the charging behavior of $P E V \mathrm{~s}$ various researches modeled different types of charging scenarios [19]. They are peak charging scenario (PCS), off-peak charging scenario (OPCS) and stochastic charging scenario (SCS). In the peak charging scenario case, all the PEVs come home after working hours and go for charging as soon as they return from the working place. This charging behavior of $P E V \mathrm{~s}$ leads to an increase in peak demand of the system because the load on the system is already peaky during those hours. In the case of OPCS, due to electricity prices implemented by the system operator the active power demand due to PEVs shift towards the light demand hours generally at midnight. In SCS, PEV so for charging at any time in a day. In this paper, PCS and OPCS are considered for the inclusion of PEVs electric demand in the system. The charging time probability distribution of PCS and OPCS are taken from [17] and given in Fig. 1. These two charging time probability functions are measured with a certain number of PEV to obtain $P_{P E V ~ j, i}$ and then integrated into daily load pattern of the distribution system which consists of residential, commercial and industrial buses.

\section{Implemented optimization algorithms}

PSO and BO bio-inspired algorithms are chosen for the optimization of the proposed objective function. From the literature, it has been observed that PSO was very old (1995) and well-proven optimization algorithm for solving engineering optimization problems because its advantages like easy to understand and implementation had driven the authors to choose this algorithm. In order to check whether the PSO had given a better solution or not, a comparative analysis has been made based on the latest (2018) optimization algorithm BO. BO algorithm is a newly developed optimization algorithm that has advantages like the new way of information propagation about the agent's fitness in the form of fragrance, no 


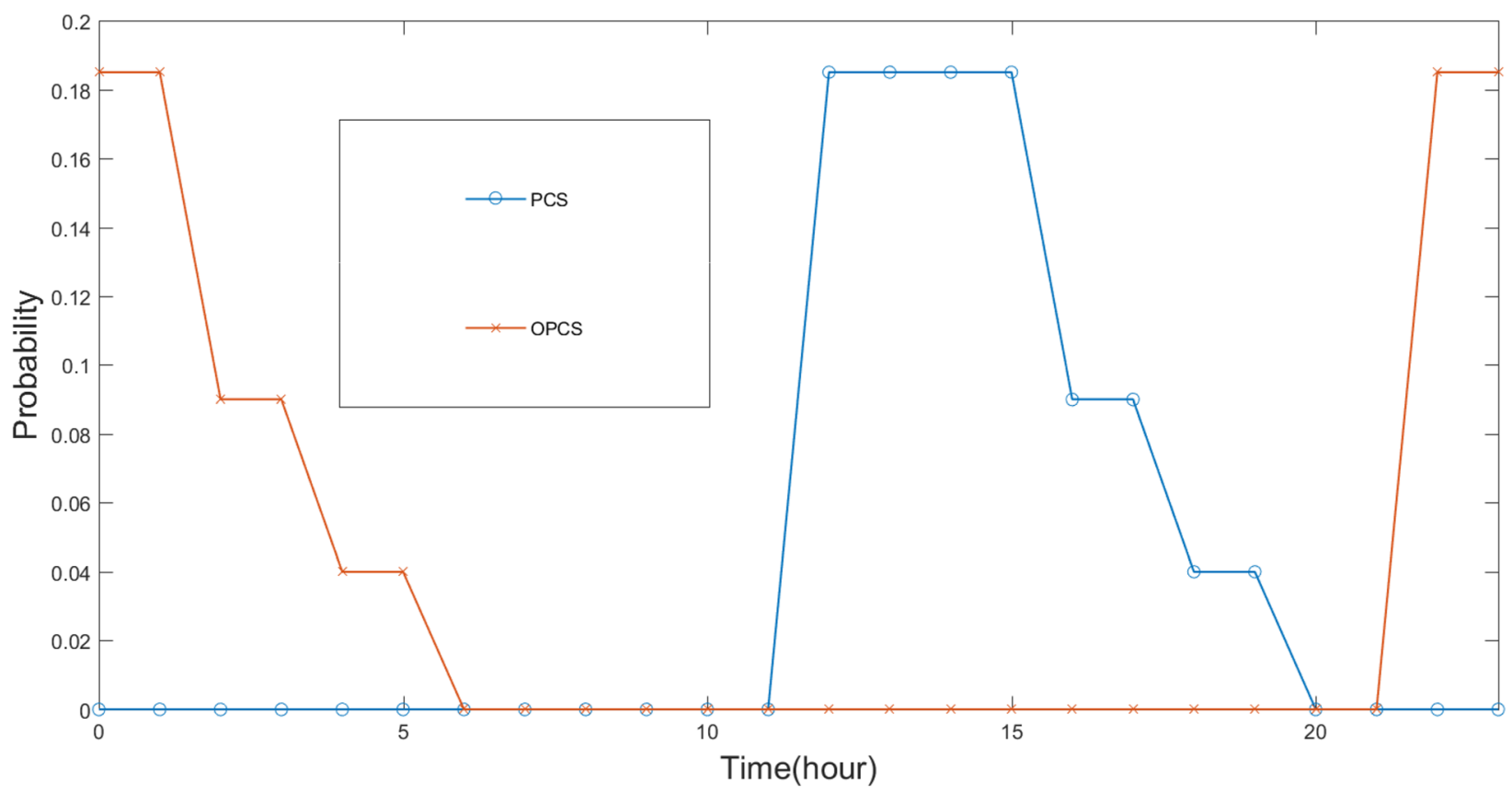

Fig. 1 PEVs probability distribution of PCS and OPCS scenarios

memory requirement i.e. no need to remember of agent's individual best positions reached so far.

\subsection{Particle swarm optimization}

The majority of heuristic and meta-heuristic algorithms have been derived from the behavior of biological systems and/or physical systems in nature. Kennedy and Eberhart introduced the concept of Particle swarm optimization (PSO) firstly in 1995 for solving continuous optimization problems [23]. The Particle Swarm optimization algorithm is a biologically-inspired algorithm motivated by the social analogy of fish or birds. The PSO algorithm starts by generating random positions for the particles, within an initialization region. Velocities are usually initialized within but they can also be initialized to zero or to small random values to prevent particles from leaving the search space during the first iterations. During the main loop of the algorithm, the velocities and positions of the particles are iteratively updated using Eq.16 and Eq.17 until a stopping criterion is met [24].

$$
\begin{aligned}
& \overline{\mathrm{V}_{\mathrm{i}}^{\mathrm{k}+1}}= \mathrm{w} * \overline{\mathrm{V}}_{\mathrm{i}}^{\mathrm{k}}+\mathrm{C}_{1} \mathrm{R}_{1}\left(\overline{\mathrm{x}_{\mathrm{i}}^{\mathrm{best}, \mathrm{k}}}-\overline{\mathrm{x}_{\mathrm{i}}^{\mathrm{k}}}\right) \\
&+\mathrm{C}_{2} \mathrm{R}_{2}\left(\overline{\mathrm{G}_{\mathrm{i}}^{\mathrm{best}, \mathrm{k}}}-\overline{\mathrm{x}_{\mathrm{i}}^{\mathrm{k}}}\right) \\
& \overline{\mathrm{x}_{\mathrm{i}}^{\mathrm{k}+1}}=\overline{\mathrm{x}_{\mathrm{i}}^{\mathrm{k}}}+\overline{\mathrm{V}_{\mathrm{i}}^{\mathrm{k}+1}}
\end{aligned}
$$

Where $\overline{\mathrm{V}}_{\mathrm{i}}^{\mathrm{k}}$ is the velocity vector of $i^{\text {th }}$ particle at $k^{\text {th }}$ iteration and each value of the vector should between $V_{i, \text { min }} \leq V_{i}^{k} \leq V_{i, \max }, \overline{\mathrm{x}_{\mathrm{i}}^{\mathrm{k}}}$ is the current position vector of $i^{t h}$ particle at $k^{t h}$ iteration, $\overline{x_{i}^{b e s t, k}}$ is the best position vector of $i^{\text {th }}$ particle up to $k^{\text {th }}$ iteration, $\overline{\mathrm{G}_{\mathrm{i}}^{\text {best, } \mathrm{k}}}$ is the best position vector among all the particles up to $k^{\text {th }}$ iteration, $W$ is the weighing function or inertia weight factor, $W$ is the weighing function or inertia weight factor, $\mathrm{C}_{1}$ and $\mathrm{C}_{2}$ are the acceleration constant, $R_{1}$ and $R_{2}$ is the random number between 0 and 1 .

\subsection{Butterfly optimization}

Butterfly Optimization is based on the ability of the butterflies to locate the source of fragrance accurately. They can also differentiate various fragrances and sense their intensities. In $\mathrm{BO}$ algorithm butterflies are the searching agents. Fitness is correlated with the intensity of fragrance that can be generated by a butterfly. The movement of butterflies in search space will change its fitness. The sharing of information between butterflies is established through the propagation of fragrance. The searching ability of a butterfly depends on the sensing capability of the fragrance. This property will decide the movement of the butterfly towards a global search or local search (random). In BOA, the fragrance is formulated as a function of the physical intensity of stimulus as follows:

$$
\mathrm{f}=\mathrm{cI}^{\mathrm{a}}
$$

Where $\mathrm{f}$ is the perceived magnitude of the fragrance, i.e., fragrance receiving property by other butterflies, $\mathrm{c}$ is the sensory modality, $\mathrm{I}$ is the stimulus intensity and $a$ is the power exponent dependent on modality, which 
accounts the varying degree of absorption. Most of the cases a \& $c \in[0,1]$. If $\mathrm{a}=1$, means there is no absorption of fragrance, i.e., the amount of fragrance emitted by a particular butterfly is sensed in the same capacity by the other butterflies (fragrance propagation in an idealized environment). Thus, a butterfly emitting fragrance can be sensed from anywhere in the domain which in turn helps to reach the global optimum easily. On the other hand, if $\mathrm{a}=0$, it means that the fragrance emitted by any butterfly cannot be sensed by the other butterflies at all. Another important parameter $\mathrm{c} \in[0, \infty]$ determines the convergence speed. The values of $a$ and $c$ are crucially affecting the convergence speed of the algorithm. For the maximization problem, the intensity can be proportional to the objective function [25].

In $\mathrm{BO}$ algorithm, the characteristics of butterflies are idealized as follows:

1. Every butterfly is supposed to emit some fragrance which enables the butterflies to attract each other (propagation of information).

2. Every butterfly will move randomly or toward the best butterfly emitting more fragrance.

3. The stimulus intensity of a butterfly is affected or determined by the topography of the objective function.

\subsection{Implementation of PSO and BO algorithms to a proposed problem}

Step 1: Initialization of problem and algorithm parameters.

In the first step, the algorithm parameters such as population size $(P O P)$, dimension of the problem $(\mathrm{d})$, the maximum number of iterations (itermax) and for PSO algorithm acceleration constants $\mathrm{c} 1, \mathrm{c} 2$ for $\mathrm{BO}$ algorithm probability switch $P$, power exponent $a$ and sensor modality care initialized. Initialize the problem parameters such as maximum total capacity of DGs injection $\left(P_{T, D G}^{\max }\right.$ ) , minimum and maximum bus voltage limits $\left(\left|U_{\text {min }}\right|\right.$, $\left.\left|U_{\max }\right|\right)$, DGs minimum and maximum active power limits $\left(P_{D G \text { min }}, P_{D G \max }\right)$, DGs location limits.

Step 2: Read the Test system Bus and Branch data, p.u demand of different types of buses for a.

day with respect to peak demand, read the probability distribution of PEVs charging scenarios PCS and OPCS. From the p.u demand of the buses and probability distribution of PEVs, kW and kVAr demand of each bus for every hour are obtained.

Step 3: Run the repetitive backward-forward sweep load flow. Calculate the daily active power.

Loss of the system without DGs $\left(P_{\text {loss, daily }}\right)$, voltage deviation index of the system without DGs $\left(V D I^{W O D G}\right)$ of the system.
Step 4: Random generation of locations for DGs placement, DGs sizes within the specified.

limits.

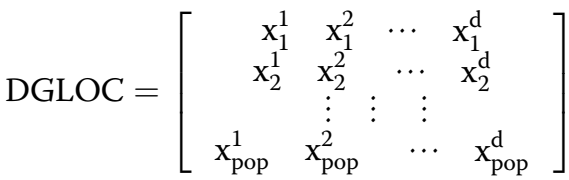

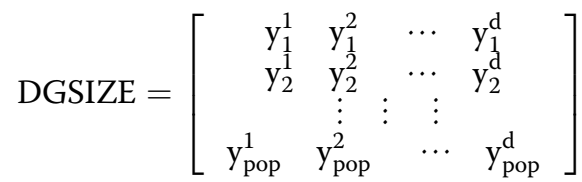

$$
\begin{aligned}
& x_{i}^{j}=x_{\min , i}+\left(x_{\max , i}-x_{\min , i}\right) * \operatorname{rand}() \\
& y_{i}^{j}=y_{\min , i}+\left(y_{\max , i}-y_{\min , i}\right) * \operatorname{rand}()
\end{aligned}
$$

Where, $x_{i}^{j}, y_{i}^{j}$ represents locations and DGs sizes, i.e., $j^{\text {th }}$ population $i^{\text {th }}$ DG location and size respectively, which is generated randomly in between the limits as $x_{\max , i}$ and $x_{\min , i}$ are the $i^{\text {th }}$ DG location limits, $y_{\max }$, $i$ and $y_{\min , i}$ are the $i^{\text {th }}$ DG size limits and $\operatorname{rand}()$ is a random number in between 0 and 1 .

$$
\text { Soln }=[D G L O C D G S I Z E]
$$

In the PSO algorithm, Soln represents a group of particles or swarms. Each particle is a solution that contains DGs locations and sizes. In BO, Soln represents a group of agents.

For the PSO algorithm along with DGs locations and sizes, generate initial velocities of particles between the minimum and maximum velocity limits.

Step 5: Fitness evaluation (Objective function).

Run the repetitive backward-forward sweep based load flow and calculate the fitness value for each initial solution using Eq. 4, Eq.5 and Eq.6 and record the gbest solution in case of $\mathrm{BO}$ algorithm, $\overline{\mathrm{x}_{\mathrm{i}}^{\text {best, } \mathrm{k}}}, \overline{\mathrm{G}_{\mathrm{i}}^{\text {best }, \mathrm{k}}}$ for the PSO algorithm.

Step 6: Set iteration count $=0$.

Step 7: The evolution procedure of PSO and BO algorithms starts from this step.

Update iteration count by 1 .

Step 8: For PSO algorithm, update the velocities of particles using Eq.16 and then update DGs.

locations and DGs size position using Eq.17.

For $\mathrm{BO}$ algorithm, calculate the fragrance $f_{N}$ for each agent or butterfly using Eq. 18 and then perform a global search and local search as follows.

If rand < probability $P$ perform global search using Eq. 24 


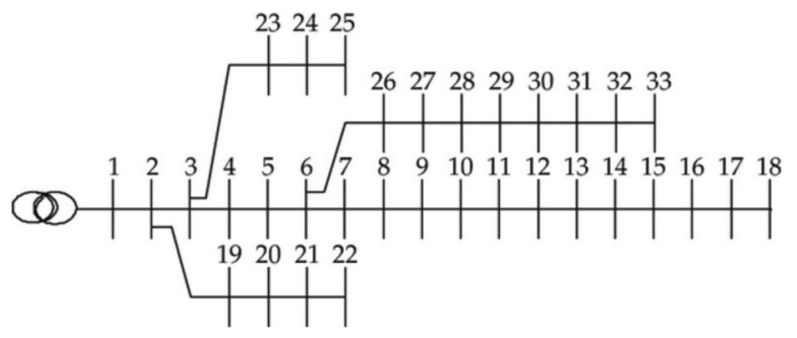

Fig. 2 Single line diagram of 33 bus test system

$$
\begin{aligned}
\operatorname{soln}_{N}^{d}(t+1)= & \operatorname{soln}_{N}^{d}(t) \\
& +\left(r^{2} * \text { gbest }-\operatorname{soln}_{N}^{d}(t)\right) * f_{N}
\end{aligned}
$$

If rand $>$ probability $\mathrm{P}$ perform a local search using Eq. 25

$$
\begin{aligned}
\operatorname{soln}_{N}^{d}(t+1)= & \operatorname{soln}_{N}^{d}(t) \\
& +\left(r^{2} * \operatorname{soln}_{j}^{d}(t)-\operatorname{soln}_{k}^{d}(t)\right) * f_{N}
\end{aligned}
$$

Where $\operatorname{soln}_{j}^{d}(t)$ and $\operatorname{soln}_{k}^{d}(t)$ are $j^{\text {th }}$ and $k^{\text {th }}$ butterflies from the solution space which belongs to the same swarm and $r$ is a random number in $[0,1]$.

Step 9: Fitness evaluation (Objective function).

Run the repetitive backward-forward sweep load flow and calculate the fitness value for each new solution using Eq. 4, Eq. 5 and Eq. 6.

Step 10: Update the gbest vector in case of BO algorithm, $\overline{x_{i}^{\text {best, }},}, \overline{G_{i}^{\text {best }, k}}$ in case of PSO.

algorithm.

Step 11: Stopping criterion.

If the iteration count reaches the maximum number of iterations, computation is terminated and prints the results. Otherwise, repeat Step 7 to Step 11.

\section{Results and discussion}

An IEEE 33 bus system has been taken for the analysis of the proposed method. The base values of the system are $100 \mathrm{MVA}$ and $12.66 \mathrm{kV}$. The single line diagram of the 33-bus system is shown in Fig. 2. Out of the 33 buses: 17 buses are residential buses; 5 buses are commercial buses and 9 buses are industrial buses. The data of the grouping of buses is given in Table 1 . The line data and bus data of the system are taken from [26]. Active and reactive power demands of the buses taken from bus data are considered as peak demands of the respective buses. Hourly active and reactive power demands for a day for each bus is obtained from typical daily load pattern of different types of buses in p.u with respect to peak demand 1 p.u is shown in Fig. 3 [27]. From Fig. 3 it has been observed that for a residential bus load demand requirement is high during the period $15.00-20.00 \mathrm{~h}$.

\subsection{Analysis of the system without PEVs load and without DGs}

Backward/forward sweep based load flow has been used for load flow studies [22]. The entire simulation has been developed in MATLAB R2017a platform using Core i5 7200U, $3.10 \mathrm{GHz}, 8 \mathrm{~GB}$ RAM. After the initial load flow run i.e. before load due to electric vehicles the following points have been observed. Daily active power demand from all the buses is $64,510 \mathrm{~kW}$. The daily active power loss of the system is $3053 \mathrm{~kW}$, the voltage deviation of the system is 1.6984 p.u. The voltage profile of the system for the base case is shown in Fig. 4. From Fig. 4, it has been observed that the lowest voltage of the system is $0.8945 \mathrm{p}$. $\mathrm{u}$ at the 18th bus occurred during the 17th hour of the day.

\subsection{Analysis of the system with PEV load and without DGs} To study the effect of additional electric power demand due to PEVs in the electric distribution system, it has been assumed that 50 PEVs per residential bus with a total of $17 * 50=850$ PEVs have been considered, where $45 \%$ of these PEVs are low hybrid vehicles equipped with $15 \mathrm{kWh}$ batteries, 25\% PEVs are medium hybrid vehicles with $25 \mathrm{kwh}$ batteries and 30\% PEVs are pure battery vehicles with 40 $\mathrm{kWh}$ batteries [17]. It is also assumed that all the electric vehicles return to the home with an SOC of $50 \%$. Therefore, total electric demand due to PEVs per residential bus per day is $50 *(15 * 45 \%+25 * 25 \%+$ $40 * 30 \%) * 0.5=625 \mathrm{~kW}$ and total electric demand needed per day due to PEVs is $625 * 17=10,625 \mathrm{~kW}$.

Table 1 Grouping of Buses data

\begin{tabular}{ll}
\hline Bus Type & Bus Numbers \\
\hline Residential buses & $2,3,5,6,7,8,9,10,13,14,15,16,17,20,21,23,24$ \\
Commercial buses & $4,11,12,18,19$ \\
Industrial buses & $22,26,27,28,29,30,31,32,33$ \\
\hline
\end{tabular}




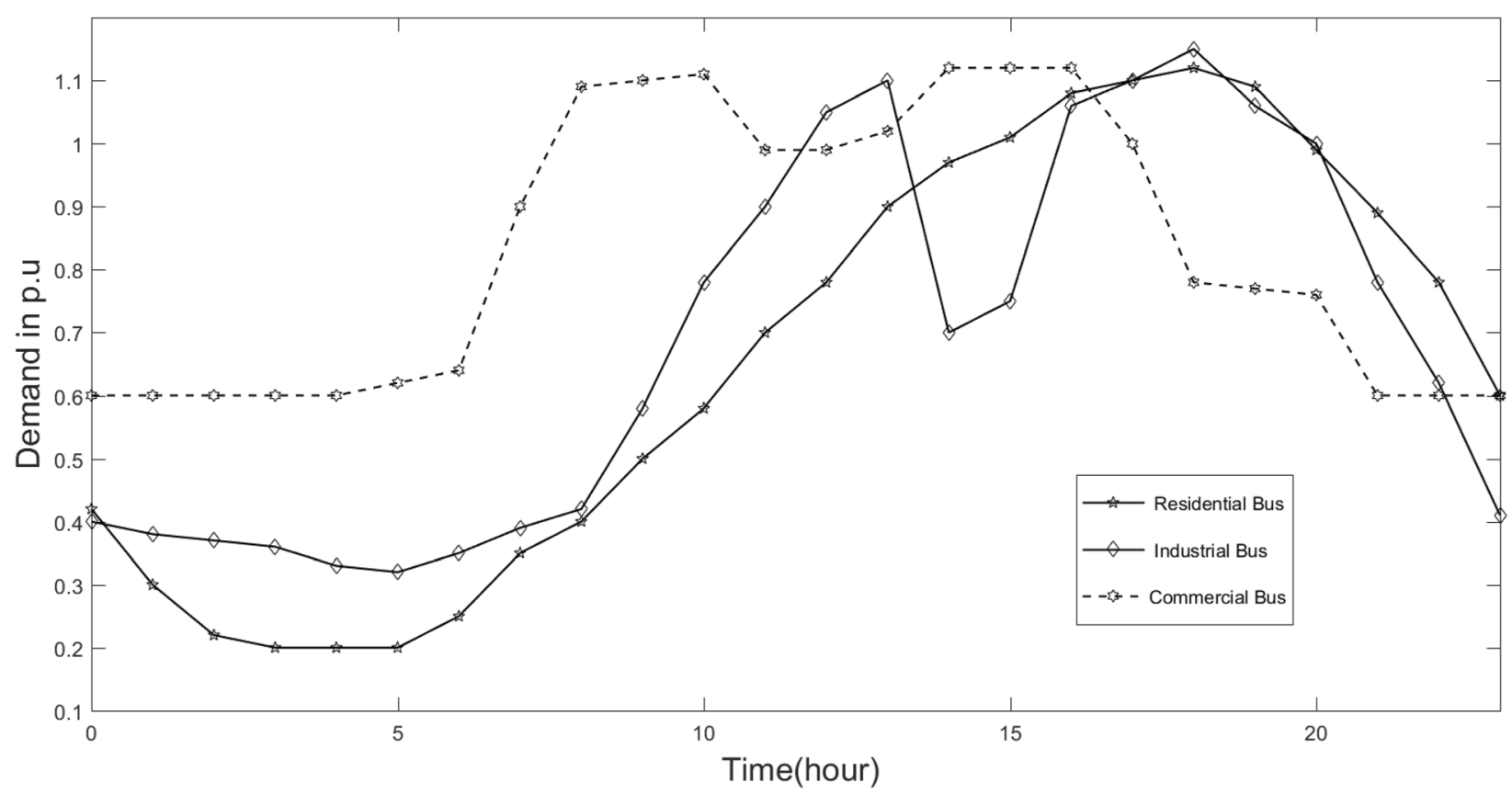

Fig. 3 Daily load pattern of different types of buses

\subsubsection{Analysis of the system with PEVs peak charging and off-peak charging scenarios}

The electric demand $625 \mathrm{~kW}$ due to 50 PEVs for each residential bus has been consumed from the slack bus (bus-1) as per the probability distribution of charging scenarios PCS and OPCS Fig. 1. The reason for not taking SCS charging scenario is that according to SCS charging scenario all the PEVs go for charging during any time in the day which means their power demand will be there on any type (residential, commercial, industrial)

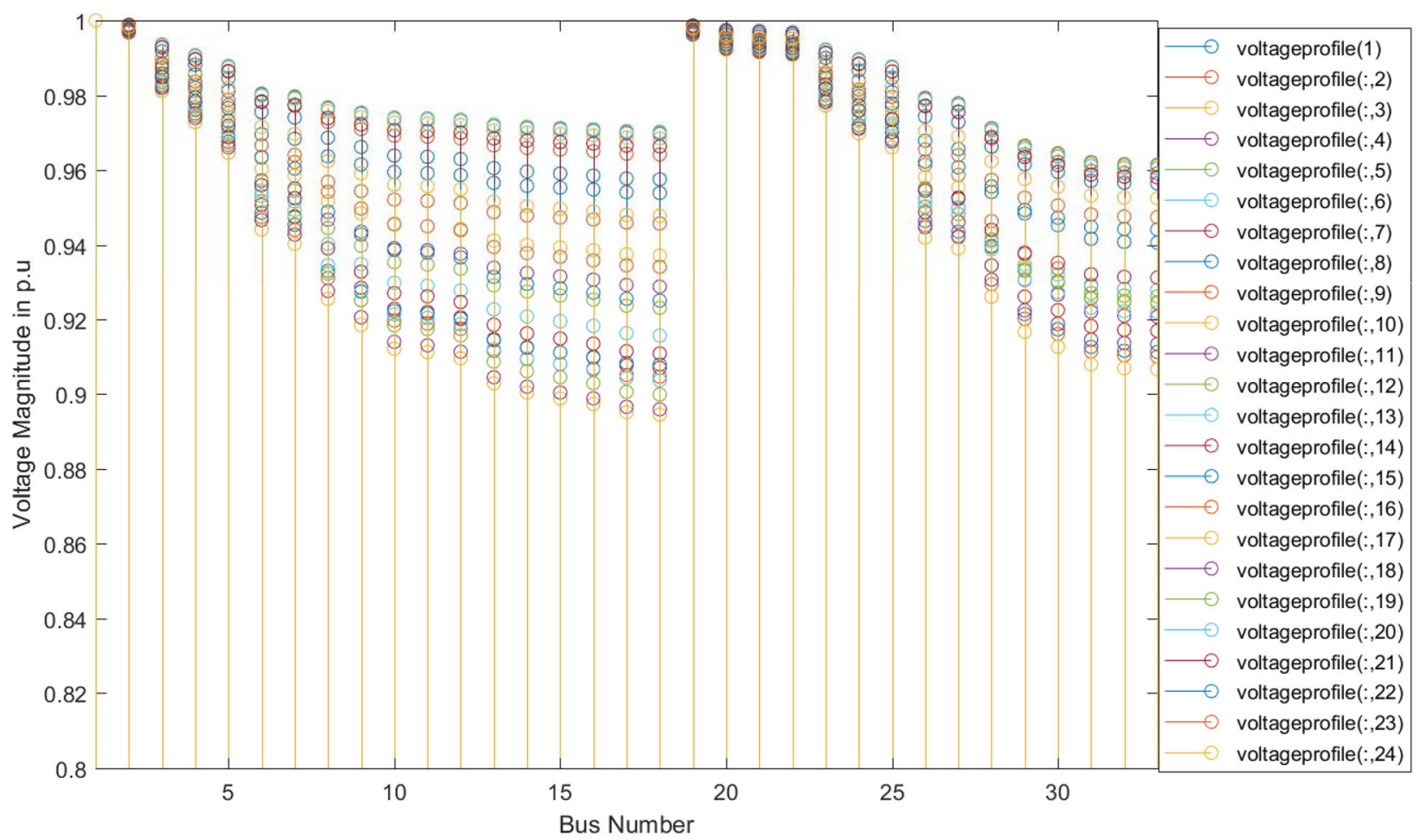

Fig. 4 Voltage profile of the system without EV load and DGs 


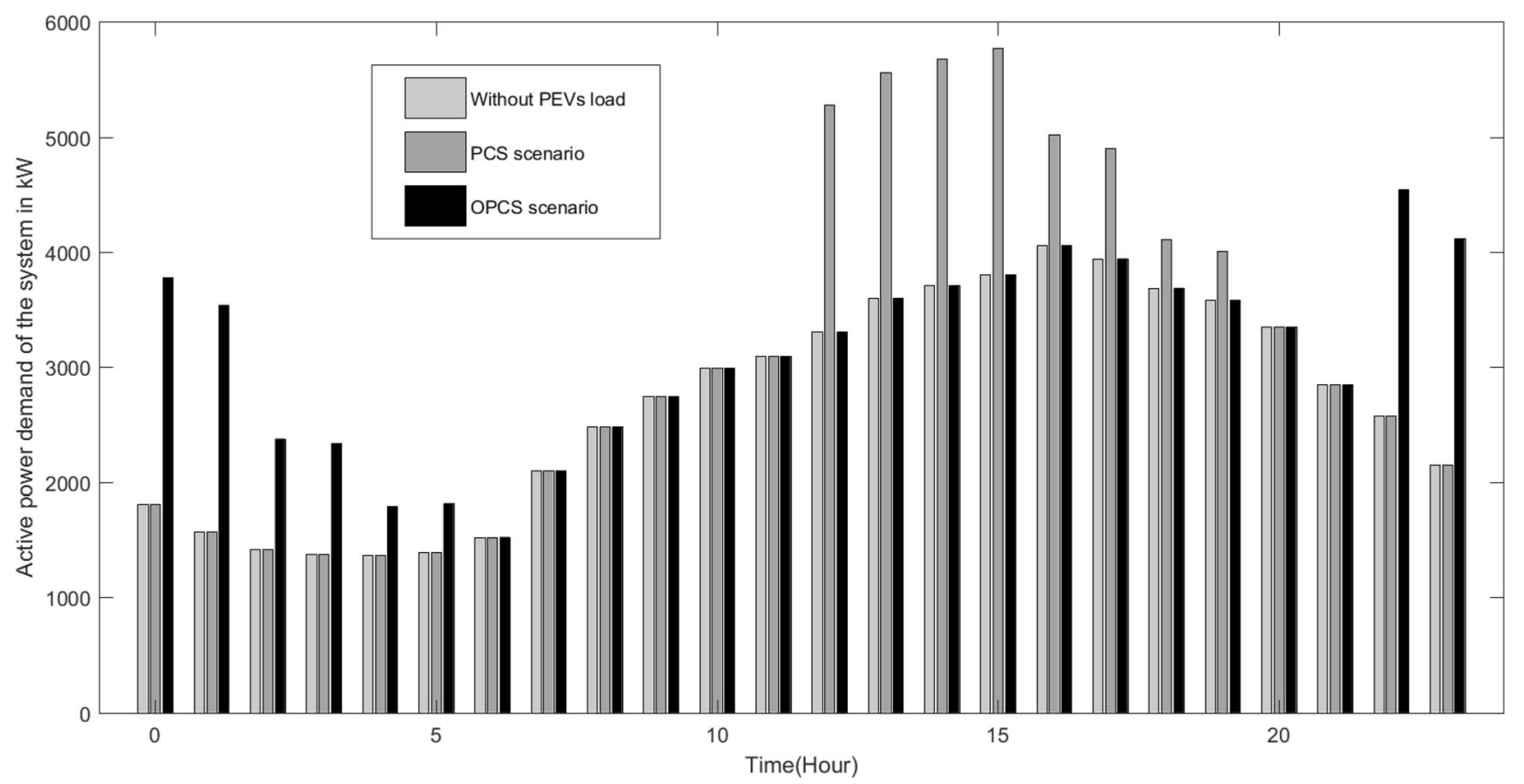

Fig. 5 Hourly active power demand of the system without and with PEVs load

of the bus, but in the paper authors considered PEVs load modeled under Residential buses only. Figure 5 shows the hourly active power demand of the distribution system for a day without PEVs and with PEVs under PCS and OPCS cases obtained from the daily load pattern of buses and charging scenarios.

Table 2 shows the comparison between various parameters between without PEVs load and with PEVs load on the distribution system and also a comparison between PCS and OPCS. From Fig. 5, it has been observed that peak active power demand of the distribution system without PEVs load, with PEVs, load charging under PCS and OPCS charging scenario is $4061 \mathrm{~kW}$ (16th hour), $5770 \mathrm{~kW}$ (15th hour) and $4541 \mathrm{~kW}$ (22nd hour) respectively. Therefore, it has been observed that

Table 2 Comparison between without and with PEVs load on test system

\begin{tabular}{|c|c|c|c|}
\hline \multirow[t]{2}{*}{ Parameters } & \multirow{2}{*}{$\begin{array}{l}\text { Without PEV } \\
\text { load }\end{array}$} & \multicolumn{2}{|c|}{ With PEV load } \\
\hline & & PCS & OPCS \\
\hline $\begin{array}{l}\text { Daily Active power loss } \\
\text { of the system in kWhr }\end{array}$ & 3053 & 4346 & 3756 \\
\hline $\begin{array}{l}\text { Voltage deviation index } \\
\text { in p.u }\end{array}$ & 1.6984 & 2.0443 & 1.9743 \\
\hline $\begin{array}{l}\text { Lowest voltage magnitude } \\
\text { in p.u }\end{array}$ & $\begin{array}{l}0.8945 \\
\text { (18th bus, } \\
17 \text { th hour) }\end{array}$ & $\begin{array}{l}0.8398 \\
\text { (18th bus, } \\
\text { 16th hour) }\end{array}$ & $\begin{array}{l}0.8729 \\
\text { (18th bus, } \\
\text { 23rd hour) }\end{array}$ \\
\hline $\begin{array}{l}\text { Active power demand } \\
\text { from the buses for a day } \\
\text { in kWhr }\end{array}$ & 64,510 & 75,135 & 75,135 \\
\hline
\end{tabular}

the peak active power demand of the system is increased by $42.08 \%$ and $11.81 \%$ in the case of PCS and OPCS charging scenarios respectively. Therefore, it is observed that the percentage increase in peak active power demand of the system is very less in the case of the OPCS charging scenario which is noteworthy.

From Table 2 it has been observed that due to PEVs electric active power demand $10,625 \mathrm{~kW}$, the distribution system is overload by $16.47 \%$ with respect to daily active power demand requirement. In case of PCS due to extra PEVs active power demand, daily active power loss of the system is increased to $4346 \mathrm{~kW}$ from 3053 $\mathrm{kW}$ which shows $42.35 \%$ increase in daily active power

Table 3 Parameters description of PSO and BO algorithms

\begin{tabular}{ll}
\hline Parameters for PSO & \\
\hline Population (pop) & 150 \\
\hline Dimension (dim) & 6 (3 DG sizes+ 3 locations) \\
Maximum number of iterations (maxit) & 150 \\
C1 & 1 \\
C2 & 2 \\
Parameters for BO & \\
Population (pop) & 150 \\
Dimension (dim) & 6 (3 DG sizes+ 3 locations) \\
Maximum number of iterations (maxit) & 150 \\
Modular modality ' $c$ ' & 0.01 \\
Power exponent 'a' & 0.1 to 0.3 \\
Probability switch ' $P$ ' & 0.5 \\
\hline
\end{tabular}


Table 4 Result analysis for optimal allocation of DGs at upf

\begin{tabular}{lll}
\hline Parameters & BO & PSO \\
\hline DG (upf) size (kW)/ & $309(10)$ & $200(12)$ \\
Bus number & $493(16)$ & $500(16)$ \\
& $699(31)$ & $776(31)$ \\
Daily active Power & 1563 & 1590 \\
Loss in kw & & \\
\% Daily active power & 58.39 & 57.66 \\
loss reduction & & \\
Voltage deviation & 0.8063 & 0.8091 \\
Index In p.u & & 0.933 \\
Lowest voltage of & 0.9353 & $(18$ th bus, \\
the system in p.u & $(18$ th bus, & 23 rd hour) \\
OF & $23 r d$ hour) & 0.4193 \\
PLRI & 0.4139 & 0.4233 \\
VDIRI & 0.4161 & 0.4098 \\
Time in sec & 0.4087 & 376.56 \\
\hline
\end{tabular}

loss whereas in case of OPCS daily active power loss of the system is increased to $3756 \mathrm{~kW}$ from $3053 \mathrm{~kW}$ which shows $23.02 \%$ increase in daily active power loss. Also in the case of PCS, the voltage deviation index is increased to 2.0443p.u and in the case of OPCS, it has increased to 1.9743 p.u. In fact, in both the scenarios (PCS \& OPCS) there is an increase in a daily active power loss of the system and voltage profile deterioration. But in the comparison between two charging scenarios, an increase in daily active power loss is $19.33 \%$ more in PCS when compared with OPCS and also the difference between voltage deviation indexes of OPCS and PCS is $0.07 \mathrm{p}$.u. From the above observations, it has been concluded that the shifting of PEVs active power demand to light electric demand hours by implementing different electricity pricing on consumers i.e. in case of OPCS shows a greater impact on improvement in reduction in peak active power demand, daily active power loss, and improvement of the voltage profile.

\subsection{Optimal placement of DGs in the distribution system with consideration of PEVs}

As concluded in the previous section the charging of PEVs through OPCS is far better when compared to PCS, we had considered the optimal placement of DGs in the distribution system with PEVs electric demand charging under OPCS only. It has been observed that there is much change in power flows (responsible for the improvement in technical parameters) in distribution lines with DGs are placed at more than two buses. It has been also observed that there was no significant change in technical parameters improvement between DGs placed at 3 buses and 4 buses and the reason might be we had chosen 33 bus systems as our test system. Therefore it is assumed that the number of DGs to be placed is fixed 3. The tuned parameters of PSO and BO algorithms are given in Table 3. From Fig. 5 it is also observed

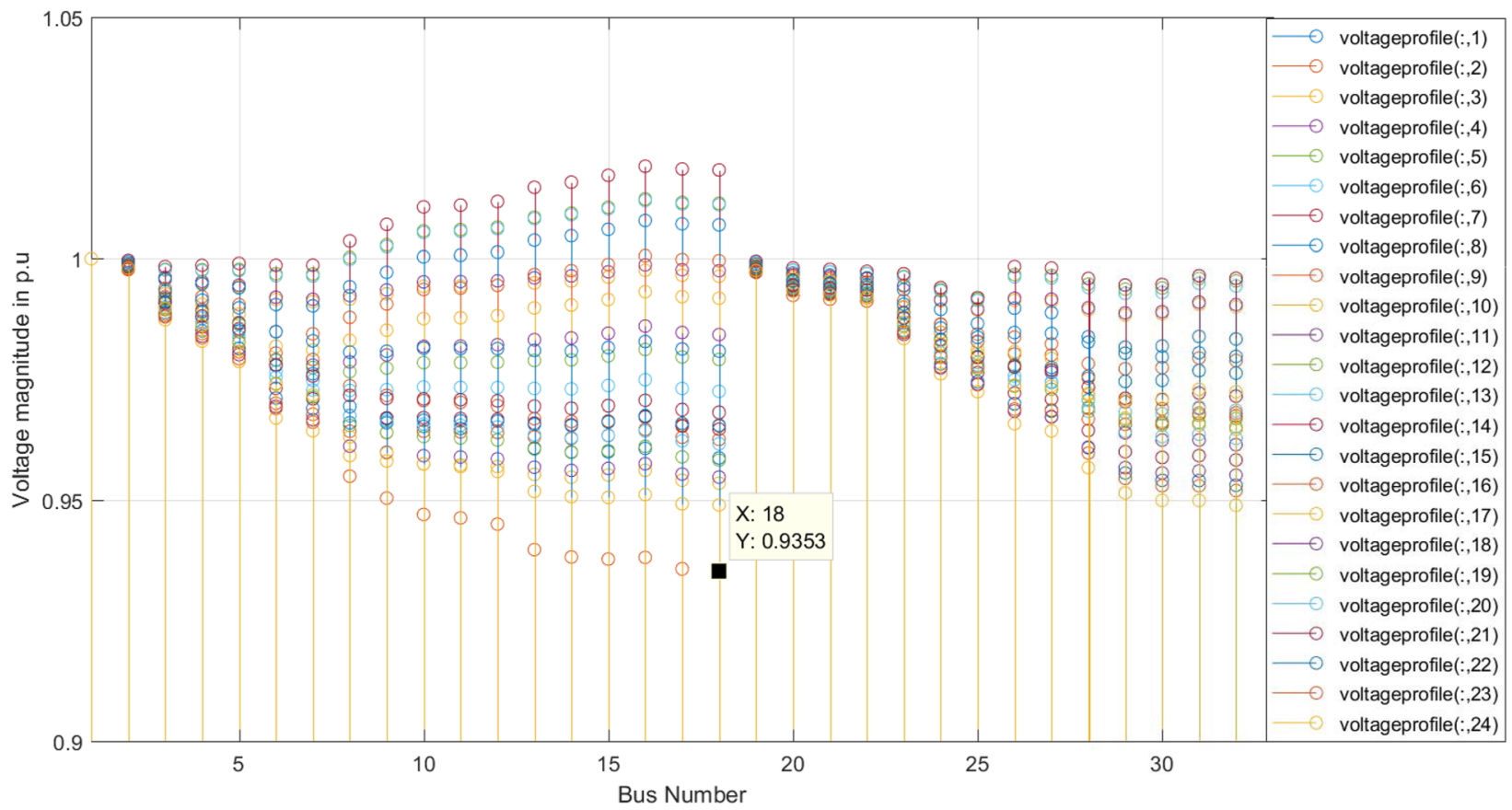

Fig. 6 Voltage profile of the test system after optima placement of DGs at upf by BO 


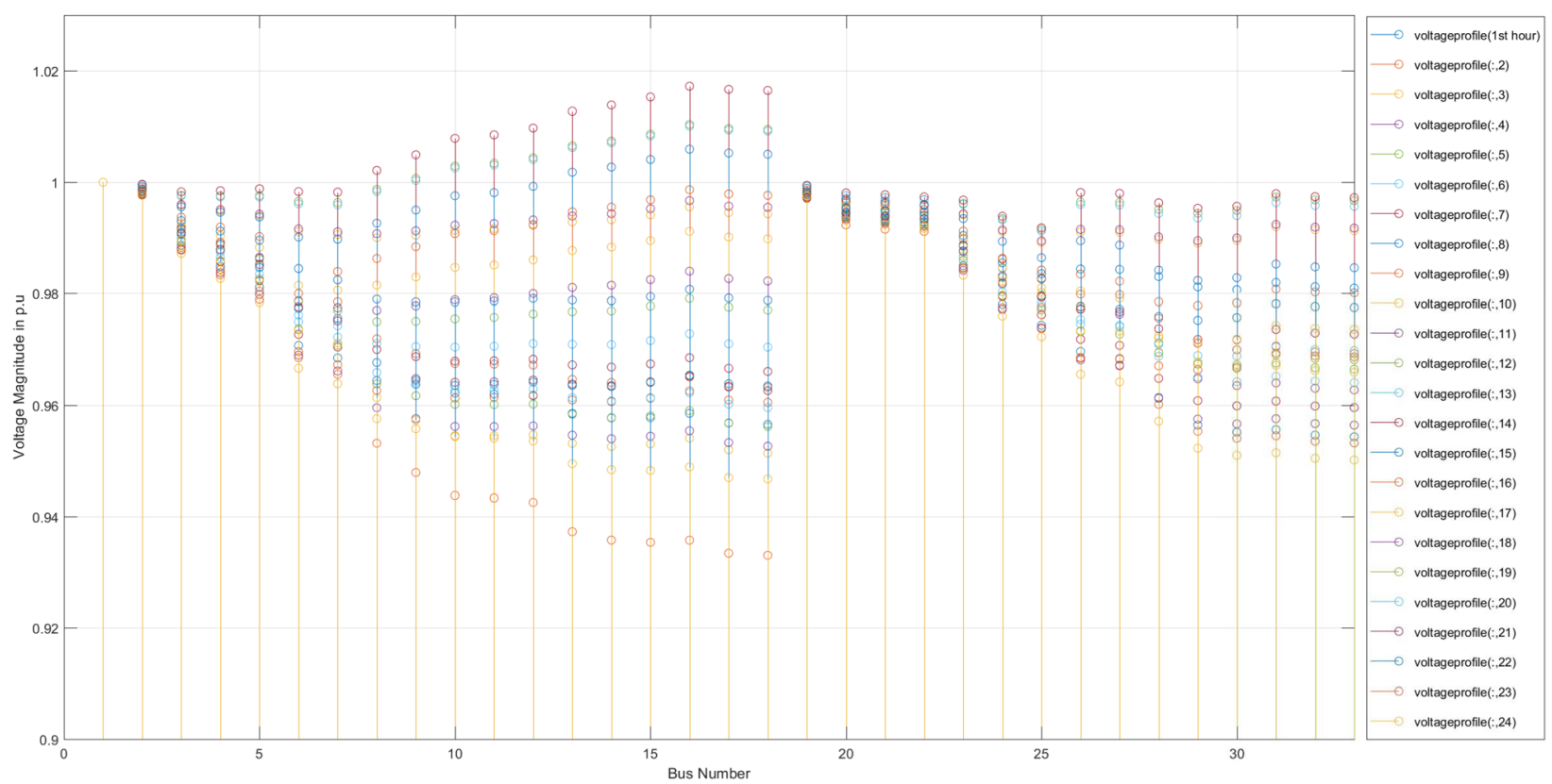

Fig. 7 Voltage profile of the test system after optima placement of DGs at upf by PSO

that the lowest active power demand with PEVs load under OPCS case is $1527 \mathrm{~kW}$ occurred during the 7 th hour of the day, therefore maximum active power injection by DGs into the distribution system is fixed to $1500 \mathrm{~kW}$. Coming to weighting factor values in the objective function, importance is given for power loss reduction because it affects economic parameters.
Therefore, weighting factors are considered as w1 = 0.7 and $\mathrm{w} 2=0.3$.

\subsubsection{Optimal placement of DGs (upf)}

Table 4 shows the optimal locations, optimal DGs (upf) sizes and various technical parameters yielded by $\mathrm{BO}$ and PSO algorithms respectively. From Table 4 it is

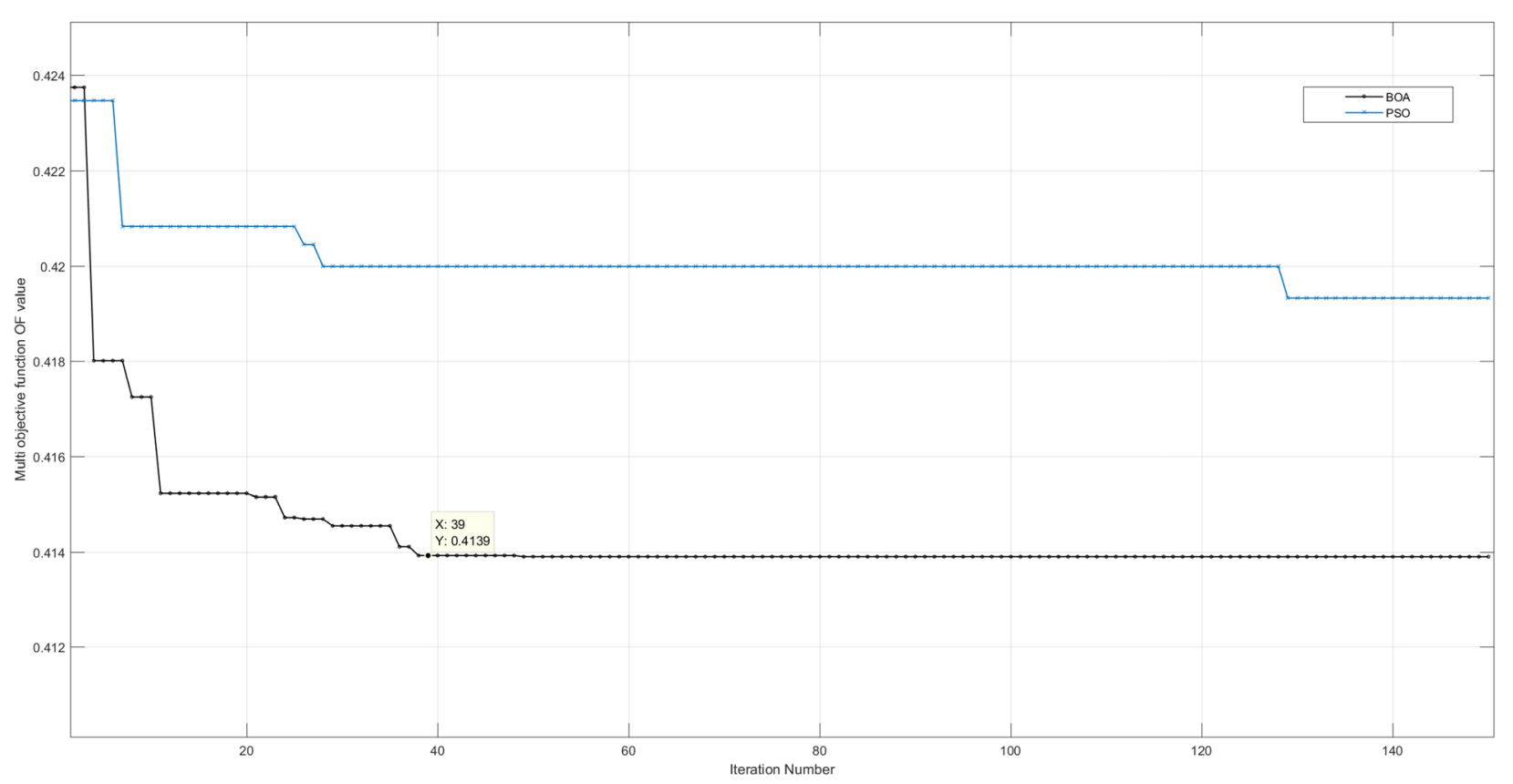

Fig. 8 Convergence graphs of BO and PSO algorithms for optimal placement of DGs at upf 
Table 5 Result analysis for optimal allocation of DGs at 0.9 pf

\begin{tabular}{lll}
\hline Parameters & BO & PSO \\
\hline DG (0.9 pf) size (kW)/ & $628(15)$ & $452(17)$ \\
Bus number & $459(30)$ & $200(10)$ \\
& $413(32)$ & $828(31)$ \\
& 870 & 916 \\
$\begin{array}{l}\text { Daily active Power } \\
\text { Loss in kw }\end{array}$ & \\
\% Daily active power & 76.84 & 75.61 \\
loss reduction & & \\
Voltage deviation & 0.5238 & \\
Index In p.u & & 0.9404 \\
Lowest voltage of & 0.9498 \\
the system in p.u & $(18$ th bus, & $(14$ th bus, \\
OF & $23 r d$ hour) & $23 r d$ hour $)$ \\
PLRI & 0.2417 & 0.2528 \\
VDIRI & 0.2316 & 0.2439 \\
Time in sec & 0.2653 & 0.2737 \\
\hline
\end{tabular}

observed that among the two algorithms, $\mathrm{BO}$ gives the best result i.e. objective function value is 0.4139 . BO yield to reduce the daily active power loss of the system to $1563 \mathrm{~kW}$ accounts for $58.39 \%$ daily active power loss reduction and the voltage deviation index is reduced to 0.8063 p. u approximately. Whereas with PSO the objective function value obtained is 0.4193 with a reduced active power loss of $1590 \mathrm{~kW}$ which accounts for a reduction in $57.66 \%$ daily active power loss and reduction of voltage deviation index 0.8091 p.u.
That is the lowest system voltage without DGs is 0.8729 p.u at the 18th bus during the 23rd hour and with optimally located DGs it is improved to 0.9353 p.u at the 18th bus during the 23rd hour. Voltage profile characteristics of the system with DGs for $\mathrm{BO}$ and PSO algorithms are shown in Fig. 6 \& Fig. 7 respectively. From Fig. 6 and Fig. 7, it is observed that obtained optimal locations and sizes of DGs result in fairly good voltage improvement at each and every bus of the system. Convergence graphs of the proposed algorithms are shown in Fig. 8. From Fig. 8 it has been observed that objective function reaches the global solution in 38th iteration for $\mathrm{BO}$ algorithm and 129th iteration for the PSO algorithm. Whereas simulation time for the evolution process for the $\mathrm{BO}$ algorithm is less than that of PSO.

\subsubsection{Optimal placement of DGs at 0.9pf}

Table 5 shows the optimal locations, optimal DGs at 0.9 pf sizes and various technical parameters yielded by $\mathrm{BO}$ and PSO algorithms respectively. The power factor of the DGs is considered as $0.9 \mathrm{pf}$. From Table 5 it is observed that the objective function values of $\mathrm{BO}$ and $\mathrm{PSO}$ are 0.2417 and 0.2528 respectively. The percentage of daily active power loss reduction of the system is $76 \%$ with $\mathrm{BO}$ and $75 \%$ with PSO. The voltage deviation index is reduced to 0.5238 p.u and 0.5404 from 1.9743p.u by BO and PSO algorithms respectively. Voltage profile characteristics of the system with DGs compensation for $\mathrm{BO}$ and $\mathrm{PSO}$ algorithms are shown

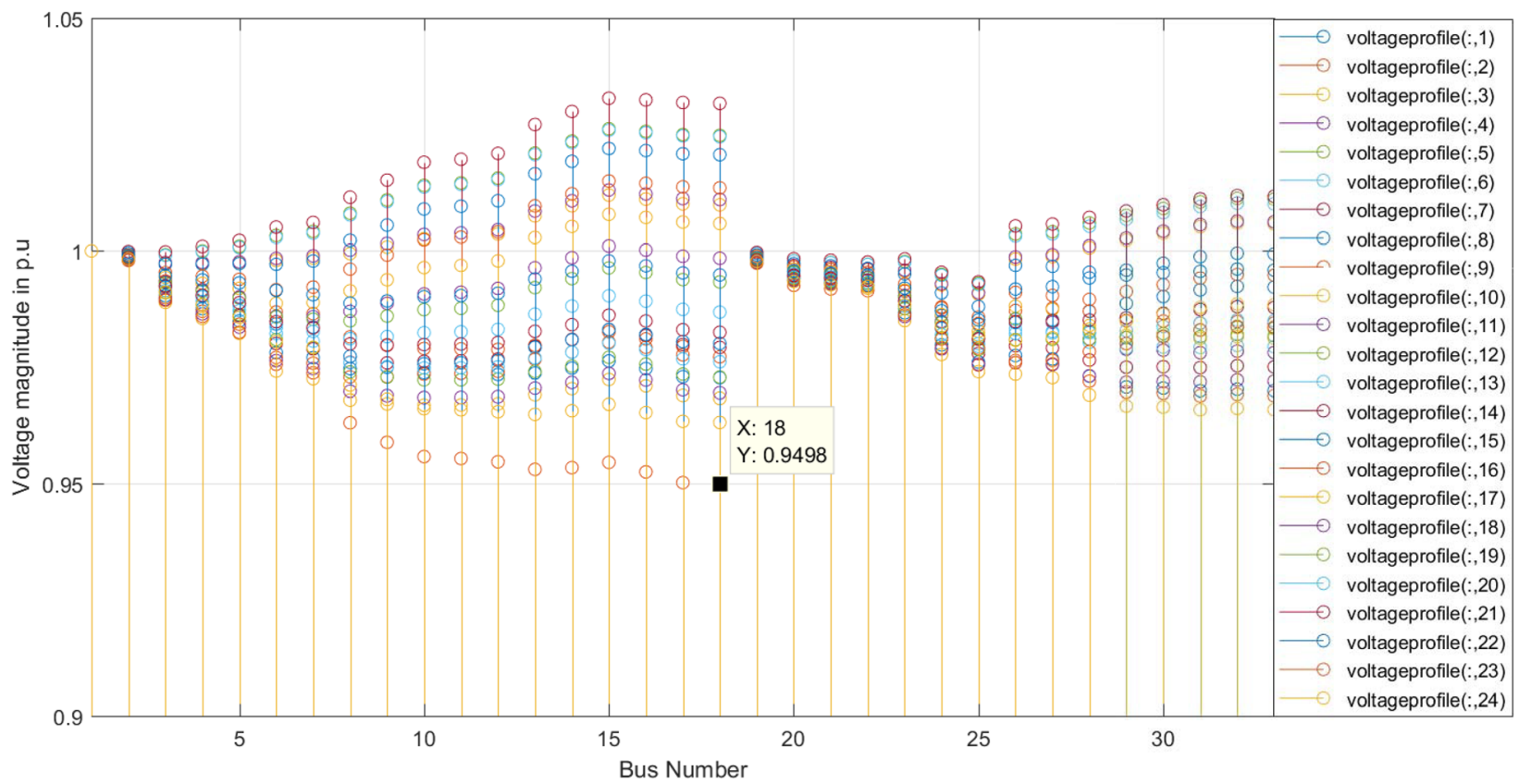

Fig. 9 Voltage profile of the test system after optima placement of DGs at 0.9pf by BO 


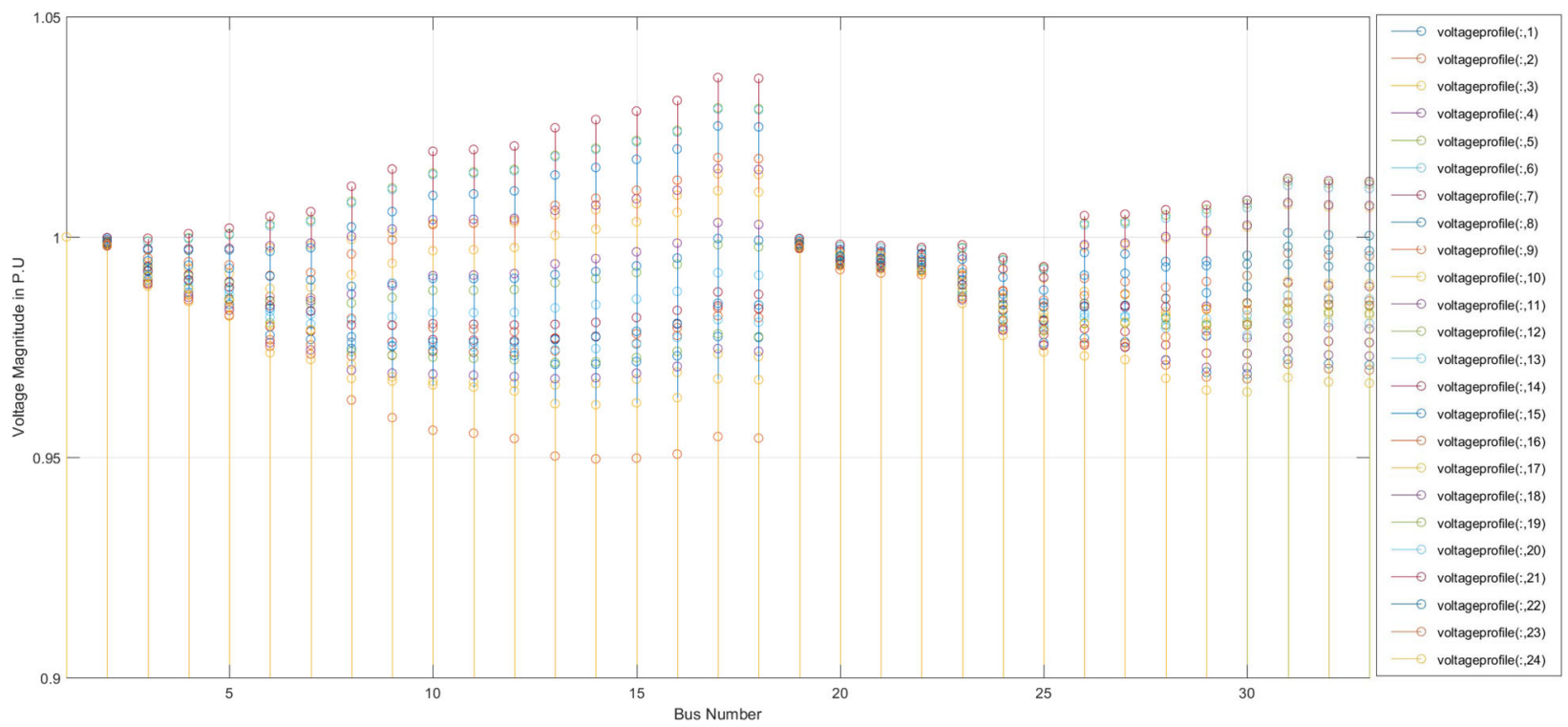

Fig. 10 Voltage profile of the test system after optimal placement of DGs at 0.9pf by PSO

in Fig. 9 and Fig. 10 respectively. Convergence graphs of the proposed algorithms are shown in Fig. 11. From Fig. 11, it has been observed that objective function reaches a global solution in 39th iteration for the $\mathrm{BO}$ algorithm and 27th iteration for the PSO algorithm. The computation time for the evolution process for $\mathrm{BO}$ is less than that of PSO.

\section{Conclusions}

In this paper, a 33-bus radial distribution test system consists of a residential, commercial, and an industrial bus is considered. A 24-h load pattern of the whole test system is obtained from the load pattern of different types of buses. Two charging scenarios PCS and OPCS had taken for the inclusion of PEVs load demand on the

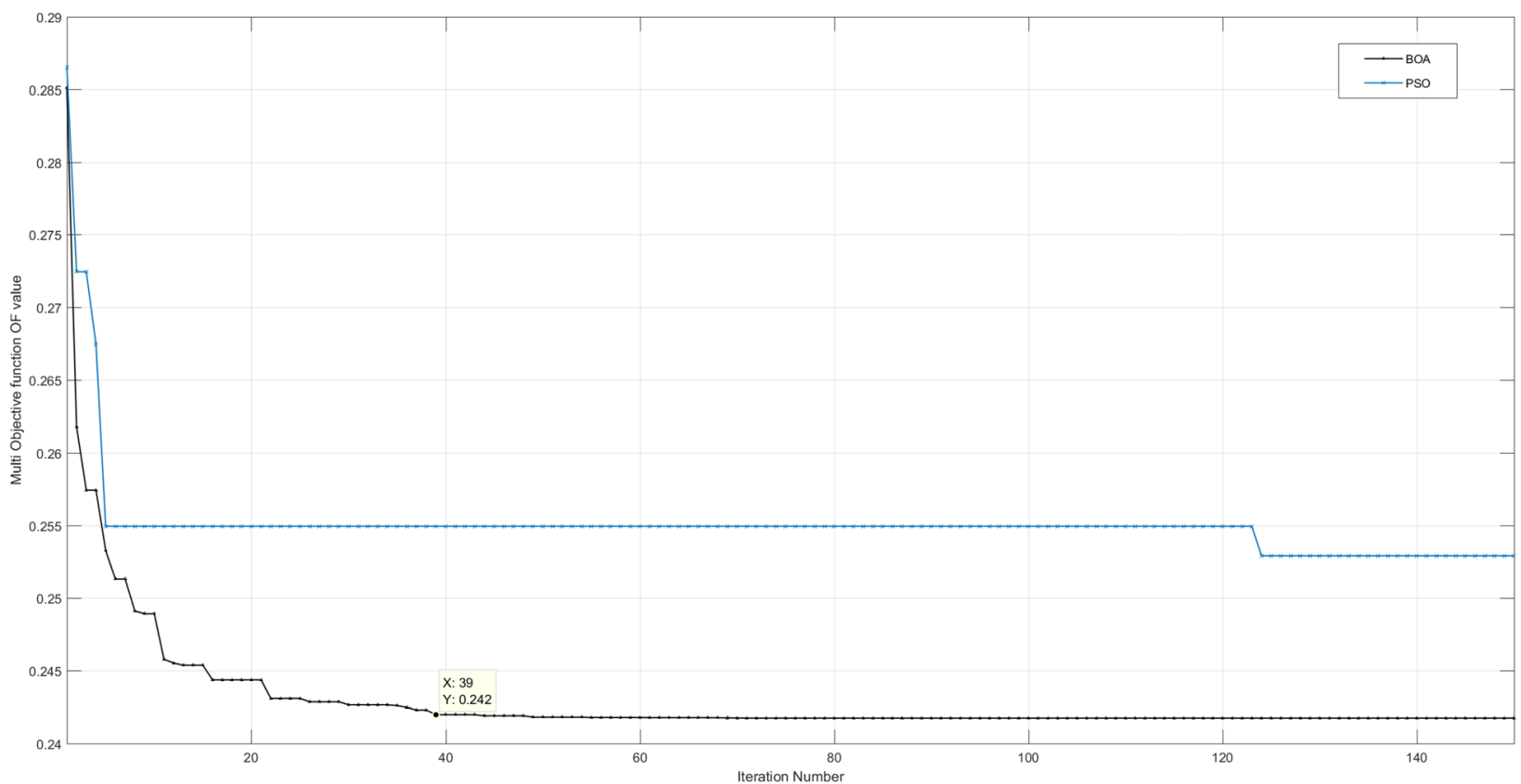

Fig. 11 Convergence graphs of BO and PSO algorithms for optimal placement of DGs at 0.9pf 
system. The impact of PEVs load demand on the system has been analyzed through technical parameters. Among the two charging scenarios PCS and OPCS, the impact of PEVs load with the OPCS charging scenario had less impact on the system technical parameters. A combined 24-h load pattern of the system including PEVs load demand with OPCS charging scenario has been considered for the optimal placement of the DGs in the system. A weighted objective function has designed to reduce the Daily active power loss and Voltage deviation index using repetitive backward/forward sweep load flow. Two algorithms BO and PSO have been selected and implemented for the minimization of the proposed objective function. From the obtained results it can be concluded that the radial distribution system performance (reduction in daily active power loss and system voltage profile) in the presence of PEVs loads including daily load pattern has improved with the optimal integration of DGs by the proposed approach. Among PSO and BO based approaches, $\mathrm{BO}$ performs better in terms of solution quality and convergence. Most of the practical/engineering optimization problems are multi-objective in nature which is found to be difficult by solving using traditional approaches. In this context, optimization algorithms will pave a way to solve the most of the nonlinear engineering optimization problems.

\section{Acknowledgments \\ Authors were indebting thankful to the Department of Science and Technology (DST-SERB), Govt. of India, New Delhi for funding this research project EEQ-2016-000263. The authors were also thankful to the Director NIT Warangal and the department of Electrical Engineering for their valuable support towards the smooth execution of the project.}

\section{Author's contributions}

Both authors equally contributed to the work presented in the paper and approved the final manuscript.

\section{Funding}

Proposal Number: EEQ-2016-000263, Financially supported by Department of Science and Technology (DST), Science and Engineering Research Board (SERB), Govt. of India, New Delhi, India.

\section{Availability of data and materials}

Not Applicable.

\section{Ethical approval and consent to participate Not Applicable.}

\section{Consent for publication}

Not Applicable.

\section{Competing interests}

The authors declare that they have no competing interests.

Received: 16 October 2019 Accepted: 10 December 2019 Published online: 15 January 2020

\section{References}

1. Rezaee, J. A. (2016). Allocation of distributed generation units in electric power systems: A review. Renew Sust Energ Rev, 56, 893-905. https:/doi.org/ 10.1016/j.rser.2015.11.086.
2. Pesaran, H. A. M., Huy, P. D., \& Vigna, K. (2016). A review of the optimal allocation of distributed generation: Objectives, constraints, methods, and algorithms. Renew Sustain Energy Rev, 1-20. https://doi.org/10.1016/j. rser.2016.10.071.

3. Kumar IS, Navuri PK. Distributed Generation \& Alternative Energy Journal An Efficient Method for Optimal Placement and Sizing of Multiple Distributed Generators in a Radial Distribution Systems 2012;37-41.

4. Rao RS, Ravindra K, Satish K, Narasimham SVL. Power Loss Minimization in Distribution System Using Network Recon fi guration in the Presence of Distributed Generation 2013;28(1):317-325.

5. Kanwar N, Gupta N, Niazi KR, Swarnkar A. Optimal distributed generation allocation in radial distribution systems considering customer-wise dedicated feeders and load patterns 2015;3:475-484. doi:https://doi.org/10. 1007/s40565-015-0169-0.

6. Injeti, S. K. (2016). A Pareto optimal approach for allocation of distributed generators in radial distribution systems using improved differential search algorithm. J Electr Syst Inf Technol. https://doi.org/10.1016/j.jesit.2016.12.006.

7. Kowsalya M. Optimal size and siting of multiple distributed generators in distribution system using bacterial foraging optimization 2014;15:58-65. doi: https://doi.org/10.1016/j.swevo.2013.12.001.

8. Andrés J, García M, José A, Mena G. Electrical Power and Energy Systems Optimal distributed generation location and size using a modified teaching - learning based optimization algorithm 2013;50:65-75. doi:https://doi.org/ 10.1016/j.ijepes.2013.02.023.

9. El-fergany A. Electrical Power and Energy Systems Optimal allocation of multi-type distributed generators using backtracking search optimization algorithm. 2015;64:1197-1205. doi:https://doi.org/10.1016/j.ijepes.2014.09.020

10. Poornazaryan B, Karimyan P, Gharehpetian GB, Abedi M. Electrical Power and Energy Systems Optimal allocation and sizing of DG units considering voltage stability, losses and load variations. Int J Electr Power Energy Syst 2016;79:42-52. doi:https://doi.org/10.1016/j.jjepes.2015.12.034.

11. Abu-Mouti, F. S., \& El-Hawary, M. E. (2011). Optimal distributed generation allocation and sizing in distribution systems via artificial bee Colony algorithm. Power Deliv IEEE Trans, 26(4), 2090-2101. https://doi.org/10.1109/ TPWRD.2011.2158246.

12. Sultana, S., \& Roy, P. K. (2014). Multi-objective quasi-oppositional teaching learning based optimization for optimal location of distributed generator in radial distribution systems. Int J Electr Power Energy Syst, 63, 534-545. https:// doi.org/10.1016/j.jijepes.2014.06.031.

13. El-Zonkoly, A. M. (2011). Optimal placement of multi-distributed generation units including different load models using particle swarm optimisation. IET Gener Transm Distrib, 5(7), 760. https://doi.org/10.1049/iet-gtd.2010.0676.

14. Abdelaziz, A. Y., Hegazy, Y. G., El-Khattam, W., \& Othman, M. M. (2015). A multi-objective optimization for sizing and placement of voltage-controlled distributed generation using supervised big bang-big crunch method. Electr Power Components Syst., 43(1), 105-117. https://doi.org/10.1080/15325008. 2014.963268.

15. Kanwar N, Gupta N, Niazi KR, Swarnkar A. Improved Cat Swarm Optimization for Simultaneous Allocation of DSTATCOM and DGs in Distribution Systems 2015;2015.

16. Ma, H., Yang, Z., You, P., \& Fei, M. (2017). Multi-objective biogeographybased optimization for dynamic economic emission load dispatch considering plug-in electric vehicles charging. Energy., 135, 101-111. https:// doi.org/10.1016/j.energy.2017.06.102.

17. Yang Z, Li K, Niu Q. A self-learning TLBO based dynamic economic environmental dispatch considering multiple plug-in electric vehicle loads 2014;2:298-307. doi:https://doi.org/10.1007/s40565-014-0087-6.

18. Ying J, Ramachandaramurthy VK, Miao K, Mithulananthan N. A review on the state-of-the-art technologies of electric vehicle, its impacts and prospects. 2015;49:365-385. doi:https://doi.org/10.1016/j.rser.2015.04.130

19. Qian, K., Zhou, C., Allan, M., \& Yuan, Y. (2011). Modeling of load demand due to EV battery charging in distribution systems. IEEE Trans Power Syst, 26(2), 802-810. https://doi.org/10.1109/TPWRS.2010.2057456.

20. Hui-ling LI, Xiao-min BAl, Wen TAN. Impacts of Plug-in Hybrid Electric Vehicles Charging on Distribution Grid and Smart Charging. 1-5.

21. Yammani, C. (2016). Optimal placement and sizing of distributed generations using shuffled bat algorithm with future load enhancement. Int Trans Electr ENERGY Syst, 274-292.

22. Injeti, S. K., Thunuguntla, V. K., \& Shareef, M. (2015). Optimal allocation of capacitor banks in radial distribution systems for minimization of real power loss and maximization of network savings using bio-inspired optimization 
algorithms. Int J Electr Power Energy Syst, 69, 441-455. https://doi.org/10 1016/j.jijepes.2015.01.040.

23. Kennedy, J., Eberhart, R. C., Kennedy, J., Eberhart, R. C., \& Kennedy, J. (1995). Particle swarm optimization. Proc Sixth Int Symp Micro Mach Hum Sci, 4, 3943. https://doi.org/10.1109/ICNN.1995.488968.

24. Bratton D, Kennedy J. Defining a standard for particle swarm optimization Citado por mí. Swarm Intell Symp 2007 SIS 2007 IEEE. 2007;(Sis):120-127. /citations?view_op=view_citation\&continue=/scholar?hl=es\&start=40\&as_ $s \mathrm{dt}=0,5 \&$ scilib=4\&citilm=1\&citation_for_view=AVzBdXOAAAAJ R3hNpaxXUhUC\&hl=es\&oi=p\%5Cn/citations?view_op=view_ citation\&continue $=/$ scholar?hl$=e s \& s t a r t=40 \&$ as $\_s d t=0,5 \% 25$.

25. Arora, S., \& Singh, S. (2018). Butterfly optimization algorithm : A novel approach for global optimization. Soft Comput. https://doi.org/10.1007/ s00500-018-3102-4.

26. Sahoo, N. C. \& Prasad, K. (2006). A fuzzy genetic approach for network reconfiguration to enhance voltage stability in radial distribution systems. Energy Convers Manag, 47(18-19), 3288-3306. https://doi.org/10.1016/j. enconman.2006.01.004.

27. Almoataz, Y. Abdelaziz. A multi-objective optimization for sizing and placement of voltage-controlled distributed generation using supervised big bang-big crunch MethodNo title. Electr Power Components Syst.

\section{Submit your manuscript to a SpringerOpen ${ }^{\circ}$ journal and benefit from:}

- Convenient online submission

- Rigorous peer review

- Open access: articles freely available online

High visibility within the field

- Retaining the copyright to your article

Submit your next manuscript at $\boldsymbol{\nabla}$ springeropen.com 